\title{
О ПРОБЛЕМАХ ДЕТСКОГО И ЮНОШЕСКОГО РЕПЕРТУАРА В ПЕДАГОГИЧЕСКОЙ И КОНКУРСНОЙ ДЕЯТЕЛЬНОСТИ
}

\author{
Л. В. Фадеева-Москалева \\ (Московский гуманитарный университет)
}

\begin{abstract}
Аннотация: В статье перечисляются наиболее частые проблемы детского и юношеского песенного репертуара, который составляется педагогами, родителями без учета возраста, опыта, характера детей. Даются практические рекомендации.
\end{abstract}

Ключевые слова: детское пение; пение; детский репертуар; юношеский репертуар; преподавание пения

\section{REPERTOIRES FOR CHILDREN AND TEENAGERS IN TEACHING AND SINGING CONTESTS}

\author{
L. V. Fadeyeva-Moskalyova \\ (Moscow University for the Humanities)
}

\begin{abstract}
The article examines the most common problems in choosing singing repertoires for children and teenagers, which is often done by their parents and instructors disregarding the singer's age, experience and temper. Also provided are practical recommendations for making a correct choice.

Keywords: children's vocal; singing for children; repertoire for children; repertoire for teenagers; teaching singing
\end{abstract}

Современные дети поют абсолютно недетские песни. Родители, а также и некоторые педагоги радуются, мол, ребенок поет песню самой... (Агилеры, Хьюстон... и пр.). А то, что поет непонятно как, непонятно о чем и непонятно зачем - это дело, видимо, пятое. К сожалению, это идет не только от педагогов, но и с экранов ТВ. Все уверения о том, что там с детьми работают и профессиональные педагоги, и психологи, остаются разговорами.

К счастью, проблема детского и юношеского репертуара в последние годы несколько смягчилась, возможно, играет роль то, что на многих конкурсах оценка за подбор репертуара вполне весомая, и играет важную роль в общей сумме баллов, набранных юным вокалистом. 
Подбор репертуара (а все педагоги это знают) - едва ли не самый сложный момент в обучении. Можно поставить дыхание, артикуляцию, научить фразировке и т. д. Но сверхзадача - сначала развивать, вести, а потом и показать ученика с песнями, которые оптимально раскроют его способности, диапазон, душу, наконец. Как много детей «не показываются» на конкурсах, не раскрываются, не производят впечатление именно из-за неверно выбранного репертуара.

Главное здесь - это, в первую очередь, соответствие содержания песни и внутреннего мира исполнителя. Яркий пример несоответствия репертуара и личности певца (точнее, певицы) - перед годовщиной Великой Победы многие девочки пели «Балладу о матери» Е. Мартынова. Пели 13-14-летние, даже двенадцатилетние. Пели, абсолютно не проживая материал, не чувствуя его, порой крича, форсируя звук, порой обливаясь слезами. Да, с воспитательной и художественной точки зрения это великолепная песня, на ее примере можно «погрузить» детей в войну, дать почувствовать, что это такое на самом деле. Но исполнять эту песню публично, можно имея только определенный жизненный опыт, пройдя страдания, потери и боль.

Иногда педагоги говорят, что дети сами хотят петь такие песни. Разумеется, это так, но в этом и состоит мастерство педагога, чтобы подобрать песни, соответствующие возрасту ребенка, его душевной и духовной зрелости. Моя мама, блестящий педагог с огромным стажем, всегда говорила: «Дайте детям быть детьми, дайте детству созреть в ребенке...»

Не зря же дети любят петь песни А. Ермолова («Плакала звезда», «Странный человек»...), мои «Королевство кошек» и множество других, которые вполне понимаемы, доступны, хотя вокально непростые.

Второй важный момент при подборе репертуара - это соответствие вокальных возможностей ученика и особенностей песни.

Диапазон - если у ученика диапазон октава, а в песне - полторы, то не надо думать, что тут споем фальцетиком, тут прошепчем, глядишь, и получится. Для классной работы, может быть, это и пройдет, но на сцене - нет. Если у ученика еще нет крепкого дыхания, а в песне длинные яркие ноты, сложные фразы, то это тоже не ваш репертуар. Известна фраза В.Хачатурова - «Показывайте не замах, а результат». Не буду оригинальна: лучше показать песню попроще, но идеально спетую и прочувствованную, чем сложную, непонятную, с частично снятой манерой известной певицы, исполняемую только потому, что песня «классная».

Отдельная тема - исполнение песен на иностранных языках. Мы все слышим на конкурсах англо-, итало-, франкоязычные песни, спетые с массой ошибок, с неправильным произношением. Петь на языках обязательно нужно, но очень серьезно подходить к этому вопросу, консуль- 
тироваться со специалистами, тщательно отслушивать оригинал. И выносить на конкурс абсолютно выученное произведение.

Часто на конкурсах есть проблемы с аранжировками. То есть аранжировками это назвать нельзя - скачанные из Интернета, несколько раз измененные (высота, темп...) гудящие «минусы». Конечно, в идеале аранжировка должна быть написана профессиональным аранжировщиком специально под исполнителя, но по материальным причинам для многих это почти невозможно. Мне нравится, когда на эстрадных конкурсах есть возможность выступать с концертмейстером, а не под фонограмму. Если концертмейстер качественно играет в эстрадной и джазовой манере, то работа с «живым» музыкантом лучше, чем работа под плохую минусовку. К сожалению, на наших конкурсах это встречается редко.

Подводя итог вышесказанному, можно уверенно сказать - в мире музыки очень много красивых, талантливых, качественных песен. Задача педагога их найти, полюбить их вместе с учеником и создать их них новую реальность - ваше яркое выступление и аудио, и видеозапись.

Фадеева-Москалева Людмила Владимировна - доцент кафедры культуры и искусства Московского гуманитарного университета, член Союза композиторов РФ. Адрес: 111395, Россия, г. Москва, ул. Юности, д. 5. Тел.: +7 (499) 374-59-40. Эл. адрес: 3730014@mail.ru

Fadeyeva-Moskalyova Lyudmila Vladimirovna, Associate Professor, Department of Culture and Art, Moscow University for the Humanities; Member, Union of Composers of Russian Federation. Postal address: 5 Yunosti St., Moscow, Russian Federation 111395. Tel.: +7 (499) 374-59-40. E-mail: 3730014@mail.ru 